\title{
Hidden Power of Trading Activity: The FLB in Tennis \\ Betting Exchanges
}

\author{
Abínzano I., Muga L. and Santamaría R. \\ Public University of Navarre and Institute for Advanced Research in Business and \\ Economics (INARBE)
}

\begin{abstract}
This paper examines the impact of trading activity on the Favourite-Longshot Bias (FLB) in tennis Betting Exchanges, using direct measures such as betting volume, average bet and standard deviation of the odds. According to predictions based on Disagreement Models, odds mispricing is positively associated with trading volume but negatively associated with the presence of institutional bettors. The FLB is also positively related to the degree of uncertainty in the market. The existence of two simultaneous markets (a "main" and an "alternative" market) in this specific sportsbetting environment has enabled us to observe that the relative amount of attention given to the favourite versus that given to the long shot is positively associated with the FLB. Finally, information is more rapidly incorporated into the odds in the market that receives more attention from bettors, an effect that is intensified by the arbitrage and hedging that occurs between the two markets.
\end{abstract}

Keywords: Betting Exchanges; Trading Activity; Favourite-longshot bias; Behavioral Finance.

JEL Code: L83, G02, G12, G14

\section{Acknowlegements:}

Financial support from the Spanish Ministry of Economy and Competitiveness, Project ECO2016-77631-R and and Fundación Caja Navarra FUNCAN-07445 are gratefully acknowledged. 


\section{Hidden Power of Trading Activity: The FLB in Tennis Betting Exchanges}

\section{1.-Introduction}

Brindley (1999) predicted that synergies between the gambling industry and the Internet would change gambling supply and consumption. The betting market structure was dominated at the time by bookmakers offering odds that were hard to compare due to limited access to information. In this context, therefore, early theoretical models (Kuypers 2000, or Levitt 2004) involving a single bookmaker treat the total betting volume for a given event as an exogenous variable. In those models, sports bettors' preferences have an ultimate impact on the prices set by bookmakers.

Internet development led in later years to a paradigm shift by which a large number of bookmakers compete in order to increase their market share. In view of this, Franck et al. (2011) developed a model where, driven by competition, bookmakers tend to offer lower odds on events that attract a high proportion of sentimental bettors. Thus, a link was established between price and trading volume in this type of market, whereby the presence of irrational bettors can lead bookmakers to bias the betting odds.

Recently, researchers in the field of sports betting have begun to direct their attention to the relationships between mispricing, trading (betting) activity and the organizational features of betting markets. In this context, much of the literature in this field has focused on price setting by bookmakers, and whether it can be interpreted as a strategy that leads them to bias the odds in the presence of informed or sentimental bettors.

The development of Internet trading platforms has undoubtedly facilitated direct competition between bookmakers, and has, even more importantly, revolutionized betting markets by enabling a form of online betting known as "Betting Exchanges". Jones et al. (2004) describe the opportunities generated for price setting and consumermarket relationships by this form of market organization.

Betting exchanges work in a way similar to order-driven financial markets. When placing bets, bettors set their own odds and state their stake, which will be exchanged if they match those of another bettor. In these markets, therefore, there is no dealer (bookmaker) to generate the spread; it is instead determined by the best bid and ask prices from the different bettors currently parked on the order book. Bookmakers' 
markets, on the other hand, are similar to price-driven financial markets in which prices are determined from bid and ask quotations made by market makers.

The impact on prices due to organizational differences between betting markets is in no way trivial. Indeed, empirical evidence has shown that betting exchange odds are better than bookmakers' odds at predicting future events (Franck et al. 2010). Put another way, price-setting errors are less common in betting exchanges, although various studies have shown that they are not entirely free of price-setting biases (Abinzano et al. 2014, 2016).

There remain large gaps in the analysis of the impact of trading activity on price setting in both organizational forms of market due to the difficulty of obtaining information on trading activity in betting markets, as noted by Flepp et al. (2016). The shortage of available data is usually overcome by using proxies, despite their very limited capacity to capture the necessary information fully and accurately.

This paper therefore aims to contribute to the existing literature by using direct measures, such as trading volume, average bet or standard deviation of the odds, to assess the influence of trading activity on price setting in the context of tennis betting exchanges. The choice of the tennis area of sports betting is due to its liquidity, the lower extent to which bettors identify with the players ${ }^{1}$ in comparison with other sports, and the simplicity of the outcome: either player A beats player B or player B beats player A. Betting exchanges also allow the possibility of betting on each match in two simultaneous markets: one for betting on the favourite (henceforth, the "main market"), where punters bet on the favourite to win (or lose); and another for betting on the longshot (henceforth, the "alternative market"), where they bet on the longshot to win (or lose) the match in question.

The existence of two distinct markets enables us to test whether betting markets for the same event, but possibly involving different types of bettors, expectations and trading activities, generate similar odds patterns, and whether trading activity plays a similar role in both markets. Note that, in efficient frictionless capital markets, price discovery should be instantaneous and contemporaneous across markets. However, frictions and non-simultaneous information, together with the risk-return characteristics of assets, in particular, the different leverage levels of assets, the different degrees of liquidity, the differences in information processing and the different transaction costs in each market 
can explain non simultaneous price discovery (see, among others, Blasco, et al., 2009 or Turkington and Walsh, 2010). In our case, the only possible differences will be in information processing or the degree of liquidity in each market, thus allowing us to test aspects of the role of trading activity.

In order to analyze pricing efficiency, this paper will focus on the FLB, as a measure of price-setting efficiency, and study its relationships with trading activity variables in the context of tennis betting exchanges.

The paper contributes to the literature in several ways. Firstly, the level of FLB is found to be higher in markets with higher trading volume and heavier attention on the favourite, and lower in markets with a higher proportion of sophisticated and informed bettors (henceforth, institutional bettors). The degree of uncertainty in the market is also found to play a key role. Indeed, confirmation has been found for a positive relationship between the standard deviation of the odds and mispricing. It is also important to emphasize that, whereas in the main market its trading activity variables contribute to explaining a significant proportion of the FLB, in the alternative market the mispricing cannot be explained by its own trading activity variables. Probably because higher trading activity enables the main market to capture and incorporate information more rapidly, it is the main-market trading activity variables that account for the bulk of the explanatory power for mispricing in the alternative market.

The remainder of the paper is divided into five more sections. Section 2 presents a review of the literature, the empirical model and the hypotheses to be tested; Section 3 describes the database for the study; Section 4 shows the main results; Section 5 provides some robustness checks; and the sixth and final section discusses the main conclusions drawn from the study.

\section{2.-Favourite-Longshot Bias, Betting Exchanges and Trading Volume}

\section{1.- Literature review}

The FLB is probably the most widely-studied manifestation of mispricing in betting markets and one that has been documented for different sports and competition frameworks (Jullien and Salanie, 2008). A variety of explanations has been offered for the FLB phenomenon in betting markets. Hurley and McDonough (1995) attribute it to 
a positive impact on the odds on favourites generated by bettors equally distributing their stakes between favourites and longshots. Snowberg and Wolfers (2010) put it down to risk preferences on the part of bettors who may be (locally) risk-lovers, as asserted by cumulative prospect theory (Tversky and Kahneman, 1992). There are also studies arguing that it is due to bookmakers adjusting the odds to protect themselves against trading with better-informed agents (Rossi 2011, Kock and Shing 2008, or Lahvička 2014), just as market makers do in price-driven financial markets (Easley and O'Hara 1987). Finally, some authors claim that the presence of bettors with heterogeneous beliefs (Gandhi and Serrano-Padial, 2015) or that of agents with cognitive biases leads to over-weighting of the chances of longshots and to bookmakers adapting to this phenomenon by lowering the odds on these less likely outcomes (Makropoulou and Markellos, 2011).

The organizational difference also leads to micro-structural differences between the two types of market (betting exchanges vs. bookmakers' markets) which will presumably affect the relationship between mispricing and trading activity. In this respect, Flepp et al. (2014a), using a sample of football betting exchanges, show that the odds in bookmakers' markets become more attractive to bettors when the liquidity for the same event is low in betting exchanges ${ }^{2}$ and Flepp et al. (2014b) show that liquidity reduces price-setting efficiency in betting exchanges for matches played at weekends, when less-informed bettors are more likely to join in the betting. In a bookmakers' market, however, Flepp et al. (2016) find no significant relationship between bookmakers' odds and trading volume in a context where there are sentimental bettors. Recently, Abinzano et al. (2016) have provided evidence of FLB in tennis betting exchanges, thus ruling out the theory that the phenomenon is basically the result of strategic behaviour by bookmakers. The fact that the effect is greater in Grand Slam matches, moreover, weakens the explanatory power of risk aversion, given that bettors' risk aversion levels are independent of the type of tournament on which they are betting. These findings leave the presence of agents with heterogeneous beliefs or cognitive biases as the most likely cause of FLB in markets of this type. In presence of this type of agents, the literature in financial markets predicts a negative relationship between liquidity and efficiency (Shleifer and Vishny, 1997). However, in a rational framework, the theoretical models point to a positive relationship due to lower transaction costs (O’Hara, 1995). 
The empirical evidence for betting markets has shown a positive relationship between liquidity and mispricing in the presence of behaviourally biased agents. Flepp et al. (2014b) find that market efficiency decreases with liquidity at weekends, when noise bettors are more likely to participate. Abinzano et al. (2014) find evidence of a positive relationship linking volume with mispricing and also with overconfidence and selfattribution biases, while finding a negative link between these two biases and the presence of institutional bettors proxied by average bet. "Average investment" and "average trade" have been used in the financial literature as proxies for the presence of institutional investors in environments such as retail and institutional mutual funds (see, for example, James and Karceski 2006, Khorana, Servaes and Tufano 2008 or SalganikShoshan 2016). Traditionally, the presence of institutional investors has been linked with market efficiency.

A mix of cognitively-biased and rational agents or the presence of investors with heterogeneous beliefs in financial markets has been linked, within the Behavioral Finance framework, with higher trading volume. Hong and Stein (2007) describe a survey of theoretical models grouped under the name of "Disagreement Models", whose main prediction is that the presence of this type of agents generates higher trading volume which in turn leads to mispricing.

Similarly, the financial literature has found less behavioural bias in institutional agents than in individual agents. De Long et al. (1990) show theoretically that the presence of a high proportion of noise traders in a financial market leads to persistent mispricing. Frazzini (2006) finds empirically that the disposition effect is not as strong in mutual fund managers as in individual investors, and Kumar (2009) shows that individual investors display stronger behavioural biases Thus, a larger presence of institutional investors should be associated with lower levels of mispricing. Since bookmakers sometimes use betting exchanges to hedge their biggest risks, their presence might also play a role in the mispricing.

Some behavioural finance models (see, among others, Daniel, Hirshleifer and Subrahmanyam, 1998 and 2001, or Hirshleifer, 2001) have shown that investors' behavioural biases are stronger among relatively hard-to-value stocks operating in informationally-sparse environments. In the same vein, Baker and Wurgler, (2006, 2007) or Kumar (2009) have shown empirically that hard-to-value and difficult-to- 
arbitrage stocks are precisely the ones on which behavioural biases, such as those driven by investor sentiment, tend to have the strongest impact.

Finally, as mentioned earlier, due to the special features of tennis betting exchanges, there are two simultaneous markets in which to place bets. According to Bekaert and Harvey (1995), markets are completely integrated if assets with the same risk have identical expected returns irrespective of the market. As a consequence, they will show the same level of FLB. If they are not completely integrated, however, they will display different levels of mispricing.

\section{2.- The empirical model}

Taking into account the results mentioned in the previous subsection, this paper aims to study the relationships between mispricing and trading activity variables in the context of tennis betting exchanges. For the purposes of this study, mispricing can be described by the following function:

$$
\text { Misspricing }=\mathrm{F}(\text { TradVol, FavAtt, InvTyp, UncLev })
$$

Where TradVol is the Trading Volume, FavAtt is the attention paid to the favourite, InvTyp is investor type; UncLev is the uncertainty level, and FLB is used as a measure of price-setting efficiency.

FLB bias is approximated using the methodology proposed by Abinzano et al. (2016), whereby implied probabilities are estimated based on the odds in each event. In line with standard procedure in the literature, implied probability is estimated by inverting the odds (Forrest and McHale, 2007; Lahvička, 2014; and Abinzano et al., 2014). The $\mathrm{AbRIP}^{\mathrm{M}}$ variable is defined as the difference between the outcome of the bet and the implied probability in the main market. To simplify the interpretation of the results, $\mathrm{AbRIP}^{\mathrm{A}}$ is defined as the inverse to $\mathrm{AbRIP}^{\mathrm{M}}$, that is, the difference between the implied probability and the outcome in the alternative market. Under the null hypothesis of absence of FLB, the difference between the two variables $\left(\mathrm{AbRIP}^{\mathrm{M}}\right.$ andAbRIP $\left.{ }^{\mathrm{A}}\right)$ should be no different from $0^{3}$. This variable was measured in the main and alternative markets with three different odds proxies: value-weighted average odds, equal-weighted average odds and high-volume odds.

Following Lahvička (2014) and Abinzano et al. (2016), dummy variables were also constructed to capture the case when the match is between players beneath the top 50 
(LOWRANK), the case when it is not a first round match (LATEROUND), and when it is a Grand Slam match or an ATP or WTA Finals (GS). These variables have proved useful in explaining the FLB, both in bookmakers' betting markets and in betting exchanges. They are used in an attempt to explain the presence of the FLB through an approximation of the level of uncertainty, the degree of media attention on the match, and the presence of sentimental bettors.

Finally, direct trading activity variables, such as betting volume, average bet, or standard deviation of the odds will be included to test the proposed hypotheses. Faced with a lack of trading activity variables, some previous studies have used appropriate dummy variables to proxy for the proportion of sentimental bettors, the degree of media attention on the event, the presence of informed agents, etc. Others have partially overcome the dearth of trading activity data by using measures such as stadium attendance figures (Franck et al. 2011) or the track records of the teams in the betting (Avery and Chevalier, 1999). The result in all cases is a more or less accurate approximation of the main variable (trading activity) under analysis.

The simultaneous existence of a main market and an alternative market, differentiated in terms of trading activity variables and the odds spread, suggests the estimation of a system of equations. The reason for selecting this method is that certain structural factors may exert an equal effect on the error terms of individually estimated equations, thus causing contemporaneous correlation between them. The system will therefore be estimated using SUR (Seemingly Unrelated Regression) methodology. The simplest empirical model is given by the following system (Model 1):

$$
\begin{aligned}
& \operatorname{AbRip}_{t}^{M}=\alpha^{M}+\beta_{1}^{M} * G S_{t}+\beta_{2}^{M} * \text { LOWRANK }_{t}+\beta_{3}^{M} * \operatorname{LATEROUND}_{t}+\varepsilon_{t}^{M} \\
& \operatorname{AbRip}_{t}^{A}=\alpha^{A}+\beta_{1}^{A} * G S_{t}+\beta_{2}^{A} * \text { LOWRANK } \\
& t
\end{aligned}
$$

where the independent variables are the dummies GS, LOWRANK, and LATEROUND.

Subsequent model specifications include trading activity variables for both markets. Specifically, AbVOL measures abnormal trading volume in the market as the actual volume traded minus the average volume traded in markets with the same values of GS, LOWRANK, LATEROUND, and YEAR ${ }^{4}$. Likewise, AbAVBET measures the average abnormal bet as the average bet in the market (total trading volume divided by the 
number of bets) minus that of its reference group and SD, which is the standard deviation of the odds in the respective market. As a control variable, the proposed model also includes SKEW, which measures the coefficient of skewness in the odds ${ }^{5}$. Finally, it also includes the variable RELATT, which measures the degree of attention on the favourite relative to that on the long shot, proxied by the quotient between the volumes of betting on a match in the main market and in the alternative market (Model 2).

$$
\begin{aligned}
\operatorname{AbRip}_{t}^{M}=\alpha^{M} & +\beta_{1}^{M} * G S_{t}+\beta_{2}^{M} * \operatorname{LOWRANK}_{t}+\beta_{3}^{M} * \text { LATEROUND }_{t}+\beta_{4}^{M} \\
& * \text { AbVOL } L_{t}^{M}+\beta_{5}^{M} * A b A V B E T_{t}^{M}+\beta_{6}^{M} * S D_{t}^{M}+\beta_{7}^{M} * S K E W_{t}^{M}+\beta_{8}^{M} \\
& * \operatorname{RELATT}_{t}+\varepsilon_{t}^{M} \\
\operatorname{AbRip}_{t}^{A}=\alpha^{A} & +\beta_{1}^{A} * G S_{t}+\beta_{2}^{A} * \operatorname{LOWRANK}_{t}+\beta_{3}^{A} * \operatorname{LATEROUND}_{t}+\beta_{4}^{A} \\
& * \operatorname{AbVOL}_{t}^{A}+\beta_{5}^{A} * A b A V B E T_{t}^{A}+\beta_{6}^{A} * S D_{t}^{A}+\beta_{7}^{A} * S K E W_{t}^{A}+\beta_{8}^{A} \\
& * \operatorname{RELATT}_{t}+\varepsilon_{t}^{A}
\end{aligned}
$$

The empirical model enables us to test the following hypotheses:

H1: There is no link between the FLB and the volume being traded in the market.

H2: There is no link between the FLB and the presence of institutional investors.

H3: There is no link between the FLB and the level of uncertainty in the market.

Under this specification, and based on the arguments set out in previous section, we expect to reject Hypothesis 1 by finding a positive relationship between AbRIP, which measures the presence of the FLB in the market, and the two measures of abnormal trading volume $\left(\mathrm{AbVOL}^{\mathrm{M}}\right.$ and $\left.\mathrm{AbVOL}^{\mathrm{A}}\right)$. If found, this relationship would confirm that higher trading volume in these markets is a proxy for the presence of agents with heterogeneous beliefs, who, according to disagreement models, would have a positive impact on mispricing.

Meanwhile, rejection of Hypothesis 2, due to evidence that the AbRip variables are negatively linked with $\mathrm{AbAVBET}^{\mathrm{M}}$ and $\mathrm{AbAVBET}^{\mathrm{A}}$, , confirms their role in increasing odds-setting efficiency. Meanwhile, the positive relationship with $\mathrm{SD}^{\mathrm{M}}$ and $\mathrm{SD}^{\mathrm{A}}$, the measures used to proxy for uncertainty, indicates that, in markets with a high level of 
uncertainty, there will be higher levels of mispricing, thus enabling us to reject Hypothesis 3.

As already noted, skewness in the odds is included as a control variable. In fact, the relationship with the odds skewness indices $\left(\mathrm{SKEW}^{\mathrm{M}}\right.$ and $\left.\mathrm{SKEW}^{\mathrm{A}}\right)$ is not obvious $a$ priori, although it would be reasonable to expect to find an opposite effect on the skewness of the odds in the main market compared to the alternative market, given the opposite directions of the bets in each market. Negative skewness observed in the main market would indicate that a bigger fraction of the odds are below the mean, that is, there is a greater number of low odds, which should be accompanied by a higher degree of FLB ${ }^{6}$.

Finally, as mentioned earlier, in tennis betting exchanges there are two simultaneous markets in which to place bets. Differences in the level of FLB can be used to proxy for the degree of integration between the two markets. If the two are fully integrated, they will show the same level of FLB. Otherwise, their levels of mispricing will be different. As market segmentation can be the result of frictions and non-simultaneous information, price differences can be explained by different degrees of liquidity and differences in information processing. Thus, we are able to test two further hypotheses. Firstly, since the level of attention on the favourite relative to that on the longshot can be approximated by the quotient between the betting volumes in the main and alternative markets (RELATT), it is worth testing whether this variable is linked to the level of FLB.

H4: There is no link between the FLB and the relative levels of attention on the favourite and the longshot.

We expect to find a positive relationship with RELATT, since this variable will capture a concentration of attention on the favourite, due to stronger media attention or the event being more a heavily focused on the favourite, and thus enable the rejection of hypothesis 4.

A further test would be to measure the degree of interaction between the two simultaneous markets. The first thing to note is the difference in trading activity, which is much higher in the main market. Assuming a certain degree of cross-market integration, and that the main market, thanks to its higher liquidity, is quicker to incorporate information, the main market variables will hold as much, if not more, 
explanatory power for pricing in the alternative market. If, on the other hand, the two markets are perfectly segmented, the main market variables will have no explanatory power at all for the price setting process in the alternative market.

H5: Trading activity variables in the main market have no explanatory power for the level of FLB in the alternative market.

Our suspicion is that, irrespective of the information reaching the market, which, the main market, as already noted, is probably quicker to incorporate, it could be arbitrage activity generated by mispricing or hedging that makes the main market variables clearly relevant for the alternative market. This would lead to the rejection of this last hypothesis.

In order to assess the degree of cross-market integration and determine whether, as advanced earlier, it is the main market variables, rather than the specific variables of the alternative market, that capture mispricing in the alternative market, we can use the following model: (Model 3).

$$
\begin{aligned}
& \operatorname{AbRip}_{t}^{M}=\alpha^{M}+\beta_{1}^{M} * G S_{t}+\beta_{2}^{M} * L O W R A N K_{t}+\beta_{3}^{M} * \operatorname{LATEROUND}_{t}+\beta_{4}^{M} \\
& \text { *AbVOL } L_{t}^{M}+\beta_{5}^{M} * A b A V B E T_{t}^{M}+\beta_{6}^{M} * S K E W_{t}^{M}+\beta_{7}^{M} * S D_{t}^{M}+\beta_{8}^{M} \\
& \text { * RELATT } t+\varepsilon_{t}^{M} \\
& \operatorname{AbRip}_{t}^{A}=\alpha^{A}+\beta_{1}^{A} * G S_{t}+\beta_{2}^{A} * \operatorname{LOWRANK}_{t}+\beta_{3}^{A} * \operatorname{LATEROUND}_{t}+\beta_{4}^{A} \\
& * A b V O L_{t}^{M}+\beta_{5}^{A} * A b A V B E T_{t}^{M}+\beta_{6}^{A} * S K E W_{t}^{M}+\beta_{7}^{A} * S D_{t}^{M}+\beta_{8}^{A} \\
& \text { * RELATT } T_{t}+\varepsilon_{t}^{A}
\end{aligned}
$$

In order to reject hypothesis 5 , this model, in which the main-market variables are used to explain mispricing, should yield better results than those obtained with model 2 .

\section{3.- Database}

The data for this study, which were drawn from the betfair.com database, are comprised of matched bets on 28,595 individual professional tennis matches played between June 2004 and June 2013. Although the Betfair database includes both pre-event (PE) and inplay (IP) betting data for each event, this study does not consider the odds on the outcome of the matches once the event has begun (IP), because they would reflect not only gamblers' prior beliefs but also information regarding match results. 
The database provides a register of all the prices traded in each market. The following variables for each match were either directly collected or computed from the database: Event identification, Event description, Winner selection, Result (1, winner or 0, loser), Total bets, Total volume, Average bet, number of different odds, standard deviation of the odds, value-weighted average odds, equal-weighted average odds, and high-volume odds (the odds at which most of the money was bet).

It is important to note that, for every match, the Betfair Company will, in addition, take either lay or back bets both on the favourite and on the long shot. Thus, there are two simultaneous markets: the "main market" where the bets are on the favourite and an "alternative market" where the bets are on the longshot.

For the purposes of this study, and in line with standard financial market practice, low liquidity events were dropped from the sample. The criterion was to drop matches with fewer than 50 crossed bets. Matches in which the calculated odds showed both players to be favourites, (the odds for both were less than 2), or both to be longshots (the odds for both were higher than 2) were also dropped. This left a final database of 24,683 matches with $14,659,235$ matched bets in the main markets and 7,289,176 in the alternative markets.

The trading activity data in the main and alternative markets are given in Table 1, where it can be seen that significantly less trading goes on in alternative markets, both in terms of numbers of bets and total trading volume, measured in pounds sterling. There are also fewer institutional bettors, as proxied by the average bet and the number of different odds traded. If these variables were to play a determining role in the mispricing process and there were no mechanism for arbitrage between the two markets, the level of FLB in each should be different.

As shown in Table 2, significant differences in trading activity variables do in fact exist for the various types of event captured by these dummy variables, which shows their lack of accuracy. In particular, it can be seen that trading volume is significantly greater, both in pounds sterling and in number of bets, for matches involving players ranked among the top 50, Grand Slam matches or circuit finals, and for matches beyond the first round. The average bet is also shown to be significantly higher in these cases. Finally, the standard deviation of the odds is significantly lower in the alternative market only for matches between players beneath the top 50 and for first-round 
matches, while it is higher for Grand Slam matches, both in the main and the alternative market.

These differences in trading characteristics across matches suggest that the variables used in previous studies might be partially correlated with others such as trading volume, the presence of institutional investors (proxied by the average bet), or assetpricing issues. The patent inaccuracy of these proxies strengthens the motivation to replace them with direct measures of trading activity, as already mentioned.

\section{Results}

\subsection{1.-Favourite-Longshot Bias}

After the removal of low liquidity events, the first step was to check the sample for actual evidence of the FLB. This was done by testing whether variables $\operatorname{AbRIP}^{\mathrm{M}}$ and $\mathrm{AbRIP}^{\mathrm{A}}$ are significantly different from zero. Table 3 shows that, for two of the three odds proxies in the main market (weighted average odds, and equally-weighted odds), there is evidence of the FLB. Even greater evidence of FLB is found in the alternative market and the effect is significant for all three odds proxies.

Table 3 also provides evidence of the fact that the FLB does not manifest with the same intensity in all types of events (Model 1). Thus, the results in panel A of Table 3 show a significant positive coefficient on the dummy variable GS, indicating that the effect is stronger in Grand Slam events. There is also a significant positive coefficient on the variable LOWRANK, showing that the effect of the FLB is greater in matches between less notable players, defined as those ranking below the top 50. The variable LATEROUND also has a positive sign, although no statistical significance is found when using the equally-weighted odds as the odds proxy.

The results for the alternative market (Panel B, Table 3) coincide with those for the main market, except that the GS variable does not reach statistical significance for the equally-weighted odds proxy. The conclusions to be drawn from Table 3 largely coincide with those reached by Abinzano et al. (2016), in that they demonstrate the existence of the FLB in betting exchanges, thus showing that the phenomenon is not exclusive to bookmakers' markets and that the bias varies in magnitude according to the type of event. 


\subsection{2.- Type of Event, liquidity and Favourite-Longshot Bias}

As can be seen from Table 2, however, the different types of event captured by the dummy variables used to obtain the estimates shown in Table 3 differ in terms of trading volume, average bet, standard deviation of the odds, and other key variables. The observed differences in the magnitude of the FLB may therefore be due to differences across event types in these variables, which could be proxying for factors such as a larger or smaller presence of institutional bettors or bettors with heterogeneous beliefs.

Model 2, therefore, was estimated for different proxies of betting exchange odds, obtaining the results displayed in Table 4. The estimates for the main market, both with and without the dummy variables, show a consistent, statistically-significant positive link between the FLB and the variable $\mathrm{AbVOL}^{7}$. This provides the expected evidence for rejecting Hypothesis 1, in favour of the existence of a significant positive link between trading volume and the level of FLB, whereby higher levels of mispricing are associated with higher trading volume proxying for the presence of agents with behavioural biases or "heterogeneous beliefs".

The results for the variable AbAVBET suggest that a stronger presence of institutional bettors, proxied by higher average bet, is negatively linked to the incidence of biases in odds setting, which points to the role in price-setting efficiency that the finance literature has attributed to institutional traders (see Jiambalvo et al., 2002 and Collins et al., 2003). These results, which would enable the rejection of Hypothesis 2, are obtained when the FLB is estimated using higher trading volume as the odds proxy.

$\mathrm{SD}$, the variable used to proxy for uncertainty surrounding the event in either of the betting markets, also shows significant coefficients when the FLB is proxied by the equally-weighted odds of all the bets placed in the market. Thus, as expected, it is possible to reject Hypothesis 3, in favour of the existence of a positive link between odds mispricing and uncertainty surrounding the event, for estimations with and without dummies. The coefficients on the control variable (SKEW) show a negative sign in all the estimations for the main market, indicating a link between negative skewness in the odds (most of the probability mass is below the mean) and stronger FLB. Conversely and as already noted, the opposite sign emerges on the coefficient of the same variable 
in the alternative market, where the bets are on the complementary probabilities of the longshot.

Finally, the coefficients on the variable used to control for the relative levels of attention on the favourite versus the long shot, (proxied by the ratio RELATT), shows the expected (positive) sign for all models and odds proxies. That is, the stronger the attention on the favourite with respect to the longshot, the higher the level of FLB; enabling the rejection of Hypothesis 4.

Little is revealed, however, by the results of the alternative market, whose trading activity variables are inadequate in explaining the FLB. In no case does the $\mathrm{R}^{2}$ measure exceed $2 \%$. In this market, the coefficients on $\mathrm{AbVOL}^{\mathrm{A}}$, the variable for trading volume which has shown to play a key role in the main market, also lack significance. Furthermore, the coefficients on the proxy for alternative market uncertainty, standard deviation of the odds, $\mathrm{SD}^{\mathrm{A}}$, behave erratically, depending upon which odds proxy is used. Finally, the coefficients on the variables RELATT and $\mathrm{SKEW}^{\mathrm{A}}$ have the expected signs (this time, positive in both cases). The coefficient for the variable AbAVBET ${ }^{\mathrm{A}}$, which proxies for the presence of sophisticated bettors, also has the expected negative sign, and is statistically significant in all cases.

\subsection{3.- Main versus Alternative market, degree of integration and Favourite-Longshot} $\underline{\text { Bias }}$

The limited explanatory power of the alternative market's trading volume variables to explain its degree of FLB may be due to the distinct characteristics of the two markets. Given that the trading involves the same probability in both cases, the reference price is very likely to be that of the market with the higher trading volume, which, in the case in hand, is the main market..

The system of equations was therefore re-estimated using the main market variables $\left(\mathrm{AbVOL}^{\mathrm{M}}, \mathrm{AbAVBET}^{\mathrm{M}}, \mathrm{SD}^{\mathrm{M}}\right.$, and $\left.\mathrm{SKEW}^{\mathrm{M}}\right)$ to replace those specific to the alternative market (Model 3). The results (Table 5) are clearly different. Firstly, Hypothesis 1 is rejected for both markets, given that the sign of the coefficient on the variable AbVOL is statistically significant and positive in all cases. This positive sign, as repeatedly noted in this paper, provides evidence of the link between market trading volume and mispricing due to the presence of bettors with "heterogeneous beliefs" or "behavioural 
biases", just as predicted by disagreement models (Hong and Stein, 2007) and consistent with the findings of Flepp el al. (2014b) and Abinzano et al. (2014).

Secondly, and for both markets, the coefficient on the variable AbAVBET is negative and robust to different odds proxies and to specifications with and without dummies. This again provides evidence for the rejection of the second null hypothesis, given that the presence of institutional bettors reduces mispricing, and thereby decreases biases in the odds (the FLB in the case that concerns us).

Thirdly, and again in both markets, the coefficients on the variable SD are robust and the estimates are positive and significant in all cases. This shows that higher uncertainty is associated with stronger FLB, enabling the rejection of hypothesis 3. Meanwhile, the coefficients on the control variable (SKEW) are found to be consistent with those in the previous estimation, that is, negative in all cases when using the odds skewness value based on main market data.

Finally, as in the previous estimation, RELATT, the variable used to control for the level of attention on the favourite relative to that on the longshot, also shows the expected sign in all cases. In contrast with the previous estimation, however, the explanatory power of the main market variables for the degree of FLB in the alternative market is much greater, as indicated by the marked improvement in the $\mathrm{R}^{2}$ values of the estimated models. These results enable us to conclude that, when there is a possibility of arbitrage between the two markets, pricing information is transmitted from one to the other, as occurs in financial markets, providing us with evidence to reject Hypothesis 5.

In summary, mispricing leading to FLB in betting exchanges, as well as being linked to dummy variables that could be proxying for factors such as attention on the favourite, the type of tournament, or uncertainty, is also linked to variables such as trading volume, the average bet, or the standard deviation of the odds. The behaviour of these links is similar to that observed in financial markets. Thus, the results show that the FLB is stronger in markets where the volume of betting is higher, the average bet is lower, and the standard deviation of the odds (proxying for market uncertainty) is higher. Thus, we can confirm that the odds do not fully capture all the relevant information, given that the variables relating to trading activity have considerable power to explain the FLB. Why this is so is hard to explain, however, because the reasons lie hidden among a large number of potential intervening variables (media attention, 
investor type, investor mix, degree of uncertainty, degree of market sentiment, etc.) all of which interact in the price-setting process. Further exploration of these issues would provide an interesting and potentially fruitful avenue for future research.

\section{5.- Robustness Checks}

To confirm the results found above, we present three robustness checks. First, White's (1980) standard errors were used on the expressions in Model 3 estimated for the main and alternative markets separately. The results, shown in Table 6, are robust with respect to those obtained in section 4, showing the FLB to be positively associated with trading volume (AbVOL) and negatively associated with the presence of institutional bettors (AbAVBET). A significant positive relationship can also be seen with the SD variable, albeit, in this case, only when the equally-weighted odds are used to proxy for FLB. This lack of significance of the SD variable is consistent with the findings obtained from the first estimation shown in Table 4.

In the alternative market, likewise, the observed links between the FLB and betting volume and average bet size are consistent with all the previous evidence provided by this paper. However, a negative coefficient emerges for the odds spread in the main market, $\mathrm{SD}^{\mathrm{M}}$, when the expressions are estimated separately.

Finally, the variable used to capture attention on the favourite (RELATT) has the expected signs in both markets, and are thus robust to all the results presented so far.

The second robustness check was applied to the results obtained for the degree of integration between the main and alternative markets when the trading activity variables for both markets were included. Given that, as already noted, prices are set simultaneously in both markets, it is reasonable to expect some degree of interaction, affecting not only their prices, but also their trading activity variables (Model 4).

$$
\begin{aligned}
\operatorname{AbRip}_{t}^{M}=\alpha^{M} & +\beta_{1}^{M} * \operatorname{LOWRANK}_{t}+\beta_{2}^{M} * \text { LATEROUND } \\
& +\beta_{5}^{M} * A b A V B E T_{t}^{M}+\beta_{6}^{M} * S D_{t}^{M}+\beta_{7}^{M} * S K E W_{t}^{M}+\beta_{8}^{M} * \beta_{4}^{M} * A b V O \text { LATT }_{t}^{M} \\
& +\beta_{9}^{M} * A b V O L_{t}^{A \perp}+\beta_{10}^{M} * A b A V B E T_{t}^{A \perp}+\beta_{11}^{M} * S D_{t}^{A \perp}+\beta_{12}^{M} * S K E W_{t}^{A \perp} \\
& +\varepsilon_{t}^{M}
\end{aligned}
$$




$$
\begin{aligned}
\operatorname{AbRip}_{t}^{A}=\alpha^{A} & +\beta_{1}^{A} * \operatorname{LOWRANK}_{t}+\beta_{2}^{A} * \operatorname{LATEROUN} D_{t}+\beta_{3}^{A} * G S_{t}+\beta_{4}^{A} \\
& * A b V O L_{t}^{M}+\beta_{5}^{A} * A b A V B E T_{t}^{M}+\beta_{6}^{A} * S D_{t}^{M}+\beta_{7}^{A} * S K E W_{t}^{M}+\beta_{8}^{A} \\
& * \operatorname{RELATT}_{t}^{M}+\beta_{9}^{A} * A b V O L_{t}^{A \perp}+\beta_{10}^{A} * A b A V B E T_{t}^{A \perp}+\beta_{11}^{A} * S D_{t}^{A \perp} \\
& +\beta_{12}^{A} * S K E W_{t}^{A \perp}+\varepsilon_{t}^{A}
\end{aligned}
$$

To avoid potential multicollinearity issues for each of the variables for the alternative market, we ran an auxiliary regression using $\mathrm{AbVOL}^{\mathrm{M}}, \mathrm{AbAVBET}^{\mathrm{M}}, \mathrm{SD}^{\mathrm{M}}$ and $\mathrm{SKEW}^{\mathrm{M}}$ as the independent variables. The residuals of these four auxiliary regressions were then used as the regressors in the system of equations in model 4, $\left(A b V O L^{A \perp}, A b A V B E T^{A \perp}, A b S D^{A \perp}, A b S K E W^{A \perp}\right)$ estimated using the SUR procedure. The results for the value-weighted odds are given in Table $7^{8}$.

In this case, the coefficients for the main market variables consistently show the expected signs and are similar to those given in Table 5. Complementing the above findings, the results show that betting volume $\left(A b V O L^{A \perp}\right)$ is positively associated and the average bet $A b A V B E T^{A \perp}$ is negatively associated with the presence of FLB, while no significant association is found between FLB and the standard deviation of the odds, $A b S D^{A \perp}$.

In conclusion, this estimation confirms that, although the main market variables provide most of the explanatory power for the impact of FLB in betting exchanges, the information contained in the alternative market transactions is also useful, revealing, as expected, a high degree of interdependence between the two markets, although prices are led by the main market. This finding, again, provides further evidence of the strong similarity that exists between betting exchanges and financial markets in terms of information flow patterns.

The third and last robustness check considers the possibility of collinearity between the variables used in the different models. This paper uses an empirical model linking the FLB with variables measuring trading activity, such as trading volume, average bet, or standard deviation of the odds. The possibility of these variables being correlated could lead to multicollinearity problems in the estimations. To address this issue, the Variance Inflation Factor (VIF) and the Condition Index (CI) were used to perform a collinearity diagnosis. While the VIF indicated no significant problems due to multicollinearity, the 
CI detected a slight problem with the variable RELATT. All the estimations were therefore repeated omitting the said variable. Table 8 presents the results for model 3 with value-weighted odds as the dependent variable. A positive relationship continues to be found with trading volume, a negative relationship with average bet, and a positive relationship with standard deviation of the odds. The overall conclusions also hold for the rest of the models and odds measurement methods.

\section{6.- Conclusions}

Analysis of the impact of trading activity on price setting in betting markets is a relevant issue and one for which the empirical evidence is scant, owing to the difficulty of obtaining direct data on the subject. Traditionally-used proxies, such as stadium attendance figures or the day of the week on which the event takes place, present major limitations when it comes to fully and accurately capturing trading activity information.

This paper approaches this issue using direct measures of trading activity, such as trading volume, average bet and the standard deviation of the odds. Specifically, it examines, within the framework of tennis betting exchanges, the links between these variables and the presence of FLB. Characteristics such as high liquidity, the bettors' lack of identification with the players in comparison with other sports, and a simple nodraw outcome, make this a particularly suitable setting for the analysis of these issues.

This context also enables the analysis of price setting in two simultaneous markets: the main market and an alternative market, thus providing an opportunity to test for similarity or differences in the odds patterns for the same event in two betting markets with different types of bettor, different expectations and different trading activity, and also the chance to determine whether between-market differences in the trading activity variables has a significant impact on prices.

The results obtained show that the degree of FLB is higher in events that attract higher betting volume and those with heavy attention on the favourite, and lower in events attracting higher proportions of institutional bettors. The observed positive link between the variable SD and mispricing informs on the relevance of market uncertainty in the price-setting process. These findings are all consistent with the hypotheses proposed in the study. 
Meanwhile, the existence of two simultaneous markets has enabled confirmation of a positive association between the relative levels of attention on the favourite and the longshot (RELATT) and the FLB. Since RELATT proxies both for stronger media attention and a heavier focus of the event on the favourite, it can be seen that at least one of these factors, and probably both, play a relevant role in explaining the level of mispricing observed in the market.

It has also been shown that the amount of information captured by the odds is directly associated with the degree of attention the market attracts from the bettors, very probably in conjunction with cross-market arbitrage and hedging. The main market variables hold explanatory power not only for the main market itself but also for the alternative market, although the results indicate that the alternative market variables also play a modest role in explaining its price-setting pattern.

The results of this analysis of betting exchanges mirror in key ways those obtained from the analysis of financial markets, suggesting the possibility of synergies resulting from the study of both types of market, since the deeper interest of the research community and the availability of data associated with financial markets will be complemented by the special characteristics of betting markets, as noted by Smith et al. (2006) or Hetherington, (2006), making them a suitable testing ground for some of the proposed theories for modelling investor behaviour in financial markets.

\section{FOOTNOTES}

\footnotetext{
${ }^{1}$ Identification with the player or team has been associated with markets in which there is a presence of sentimental bettors, and found to have a significant impact on the odds offered by bookmakers in betting on football matches (Franck et al. 2011).

${ }^{2}$ These results qualify previous evidence that Bookmakers were less efficient than betting exchanges when it comes to price setting (Franck et al. 2010, Smith et al. 2009).

${ }^{3}$ Following the redefinition of AbRIP ${ }^{\mathrm{A}}$, the results for both variables $\left(\mathrm{AbRIP}^{\mathrm{M}}\right.$ and $\mathrm{AbRIP}^{\mathrm{A}}$ ) need to be positive in order to indicate the presence of FLB.

${ }^{4}$ In view of the increase both in betting volume and in average bet over the sample period, the YEAR variable was included to split the data for the "abnormal" variables by year. The increase is possibly due to the growth of the industry during the study period.

${ }^{5}$ These variables can be measured using data from either the main or the alternative market, as denoted in the expressions by the superscript $\mathrm{M}$ or A, respectively.

${ }^{6}$ Odds skewness in the long shot market must be interpreted in inverse manner, given that this is where punters bet on the long shot to win (or lose) and higher odds mean less likelihood of the longshot winning, and therefore more likelihood of the favourite winning.

${ }^{7}$ The conclusions reached when using the variables for volume traded in the market and average bet (measured in absolute terms) are similar to those presented in the paper, showing the FLB to be positively
} 
associated with the volume traded and negatively associated with the average bet. These results are available upon request from the authors.

${ }^{8}$ The conclusions drawn from the estimates of FLB using equally-weighted odds are fully consistent with those drawn from estimates using the odds with the highest betting volume. They are available upon request from the authors. 


\section{REFERENCES}

Abinzano, I., Muga, L., Santamaria, R. (2014) "Behavioral Biases Never Walk Alone: An Empirical Analysis of the Effect of Overconfidence on Probabilities", Journal of Sports Economics, online first doi:10.1177/1527002514560575.

Abinzano, I., Muga, L., Santamaría, R. (2016) "Game, Set and Match: The favouritelongshot bias in tennis betting exchanges" Applied Economics Letters, 23, 605-608.

Baker, M., Wurgler, J. (2006) "Investor Sentiment and the Cross-Section of Stock Returns", Journal of Finance, 61, 1645-1680.

Baker, M., Wurgler, J. (2007) "Investor Sentiment in the Stock Market", Journal of Economic Perspectives, 21, 129-151.

Bekaert G., Harvey C.R. (1995) “Time-varying world market integration” Journal of Finance, 50, 2, 403-444.

Blasco N., Corredor P., Santamaría R. (2009) "Information spillovers between derivative markets with differences in transaction costs and liquidity" Applied Economics Letters, 16, 1039-1047.

Brindley, C. (1999) “The marketing of gambling on the Internet”, Internet Research, 9, 4, $281-286$.

Collins, D.W., Gong, G., Hribar, P. (2003), "Investor Sophistication and the Mispricing of Accruals", Review of Accounting Studies, 8, 251-276.

Daniel, K.,Hirshleifer, D., Subrahmanyam, A. (1998) "Investor Psychology and Security Market Under and Overreactions”, Journal of Finance, 53, 1839-1885.

Daniel, K., Hirshleifer, D., Subrahmanyam, A.(2001) "Overconfidence, Arbitrage, and Equilibrium Asset Pricing" Journal of Finance, 56, 921-965.

Delong, J., Shleifer, A., Summers, L., Waldmann, R. (1990) "Noise trader risk in financial markets" Journal of Political Economy, 98, 703 - 738.

Easley, D., O’Hara, M. (1987) "Price, trade, size and information in securities markets" Journal of Financial Economics, 19, 69 - 90. 
Flepp, R., Nüesch, S., Franck, E. (2014a) "The liquidity advantage of the quote-driven market: Evidence from the betting industry" Working paper. Available at SSRN: http://ssrn.com/abstract=2371185.

Flepp, R., Nüesch, S., Franck, E. (2014b) "Liquidity, market efficiency and the influence of noise traders: Quasi-experimental evidence from the betting industry" Working paper. Available at SSRN: http://ssrn.com/abstract=2371204.

Flepp, R., Nüesch, S., Franck, E. (2016) "Does bettor sentiment affect bookmaker pricing?” Journal of Sports Economics, 17 (1), 3 - 11.

Forrest, D., McHale, I. (2007) “Anyone for Tennis (betting)?” The European Journal of Finance, 13, 751-768.

Franck, E.P., Verbeek, E., Nüesch, S. (2010) "Prediction Accuracy of Different Market Structures - Bookmakers Versus a Betting Exchange", International Journal of Forecasting, 26, 448-459.

Franck, E., Verbeek, E., Nüesch, S. (2011) "Sentimental preferences and the organizational regime of betting markets", Southern Economic Journal, 78, 502-518.

Frazzini, A. (2006) "The disposition effect and under-reaction to news" Journal of Finance, 61, 2017 - 2046.

Ghandi, A., Serrano-Padial, R. (2015), "Does belief heterogeneity explain asset prices?: The case of Longshot bias". Review of Economic Studies, 82, 156-186.

Hetherington, A. (2006) "Betting against efficiency: Behavioral Finance in an NFL Gambling Exchange" Working paper. Available at SSRN: http://ssrn.com/abstract=881514.

Hirshleifer, D. A. (2001) “Investor Psychology and Asset Pricing”, Journal of Finance, 56, 1533-1597.

Hong, H., Stein, J.C. (2007) "Disagreement and the Stock Market". Journal of Economic Perspectives, 21, 109 - 128.

Hurley, W., McDonough, L. (1995) “A note on the Hayek Hypothesis and the favouritelongshot bias in pari-mutuel betting”. American Economic Review, 85, 949 - 955. 
James, C., Karceski, J. (2006) "Investor monitoring and differences in mutual fund performance", Journal of Banking and Finance, 30, 2787-2808.

Jiambalvo, J., Rajgopal, S., Venkatachalam, M. (2002) "Institutional ownership and the extent to which stock prices reflect future earnings", Contemporary Accounting Research, 19, 1, 117-145.

Jones, P., Hillier, D., Turner, D., Comfort, D. (2004) "Betting on the exchanges: changing customer relationships in the sports betting market in the UK", Management Research News, 27, 95 - 103.

Jullien, B. Salanié, B. (2008) "Empirical evidence on the preferences of racetrack bettors" in Efficiency of Sport and Lottery Markets: Handbooks in Finance Series (Hausch, D.B., and Ziemba, W.T. eds; Elesevier).

Khorana, A., Servaes, H., Tufano, P. (2008) "Mutual Fund Fees Around the World", Review of Financial Studies, 22, 1279-1310.

Kock, A.K., Shing, H.F. (2008) "Bookmaker and pari-mutuel betting: Is a (reverse) favourite-longshot bias built-in?". The Journal of Prediction Markets, 2, 29-52.

Kumar, A. (2009) "Hard-to-Value Stocks, Behavioral Biases, and Informed Trading", Journal of Financial and Quantitative Analysis, 44, 1375-1401.

Kuypers, T. (2000) "Information and Efficiency: an empirical study of a fixed odds betting market" Applied Economics, 32, 1353 - 1363.

Lahvička, J. (2014) "What causes the favourite-longshot bias? Further evidence from tennis” Applied Economic Letters, 21, 90-92.

Levitt, S. (2004) "Why are gambling markets organized so differently from financial markets?"Economic Journal, 114, 223 - 246.

Makropoulou, V., Markellos R.N. (2011) "Optimal price setting in fixed-odds betting markets under information uncertainty". Scottish Journal of Political Economy, 58, 519 $-536$.

O’Hara, M. (1995) “Market microstructure theory” Blackwell Publishers Ltd.

Rossi, M. (2011) "Match rigging and the favorite longshot bias in the Italian Football betting market”. International Journal of Sport Finance, 6, 317 - 334. 
Salganik-Shoshan, G. (2016) "Investment flows: Retail versus institutional mutual funds", Journal of Asset Management, 17, 34-44.

Smith, M.A., Paton, D., Vaughan-Williams, L. (2006) "Market efficiency in person to person betting” Economica, 73, $673-689$.

Smith, M.A., Paton, D., Vaughan-Williams, L. (2009) "Do bookmakers possess superior skills to bettors in predicting outcomes?" Journal of Economic Behavior and Organization, 71,539- 549.

Shleifer, A., Vishny, R. (1997) "The limits of arbitrage" Journal of Finance, 52, 35 55.

Snowberg, E., Wolfers, J. (2010) "Explaining the Favorite-Long Shot Bias: Is it RiskLove or Misperceptions?". Journal of Political Economy, 118, 723 - 746.

Turkington T., David Walsh D. (2010)“Informed traders and their market preference: Empirical evidence from prices and volumes of options and stock". Pacific-Basin Finance Journal, 8 (5), 559-585.

Tversky, A., Kahneman, D. (1992) “Advances in Prospect Theory: Cumulative Representation of Uncertainty", Journal of Risk and Uncertainty, 5, 297 - 323.

White, H. (1980) "A Heteroskedasticity-Consistent Covariance Matrix Estimator and a Direct Test for Heteroskedasticity", Econometrica, 48, 817-838. 


\section{TABLE 1}

This table compares betting characteristics for the main and alternative markets, including number of events in the sample (EVENTS), average number of bets in each market (NBETS), average bet calculated as total betting volume over number of bets (AVBET), total betting volume in pounds sterling (VOLTOT), average number of different odds (NODDS), and the standard deviation of the odds (SD). ${ }^{* *}$ and *denote significance at the 5\% and $10 \%$ levels, respectively

\begin{tabular}{crrrrrrr}
\hline \multicolumn{1}{c}{ TOTAL SAMPLE AVERAGE CHARACTERISTICS } & & & & \\
\hline & EVENTS & NBETS & AVBET & VOLTOT & NODDS & SD \\
MAIN MARKET & 24683 & 593.91 & 193.71 & 146567.62 & 22.93 & 1.62 \\
ALTERNATIVE MARKET & 24683 & 295.31 & 40.32 & 18181.43 & 19.00 & 6.54 \\
DIF & & $298.60 * *$ & $153.39 * *$ & $128386.19 * *$ & $3.93 * *$ & $-4.92 * *$ \\
\hline
\end{tabular}




\section{TABLE 2}

This table compares betting characteristics for the main and alternative markets in matches with low-ranking players versus matches with high-ranking players (PANEL A), in first round matches versus later round matches (PANEL B) and in Grand Slam events versus non Grand Slam events (PANEL C). The characteristics include the number of events in the sample (EVENTS), average number of bets in each market (NBETS), average bet calculated as total betting volume over number of bets (AVBET), total betting volume in pounds sterling (VOLTOT), average number of different odds (NODDS), and the standard deviation of the odds (SD). ** and * denote significance at the $5 \%$ and $10 \%$ levels, respectively

\begin{tabular}{|c|c|c|c|c|c|c|c|c|c|c|c|}
\hline \multicolumn{12}{|c|}{ PANEL A LOWRANK } \\
\hline MAIN MARKET & EVENTS & NBETS & & AVBET & & VOLTOT & & NODDS & & SD & \\
\hline 1 & 9091 & 436.52 & & 103.84 & & 52289 & & 24.53 & & 1.44 & \\
\hline 0 & 15592 & 685.66 & & 246.11 & & 201537 & & 21.99 & & 1.73 & \\
\hline DIF & & -249.14 & $* *$ & -142.27 & ** & -149248 & ** & 2.54 & ** & -0.29 & \\
\hline ALTERNATIVE MARKET & EVENTS & NBETS & & AVBET & & VOLTOT & & NODDS & & SD & \\
\hline 1 & 9091 & 231.53 & & 38.51 & & 11357 & & 19.9 & & 3.99 & \\
\hline 0 & 15592 & 332.51 & & 41.39 & & 22160 & & 18.48 & & 8.03 & \\
\hline DIF & & -100.98 & $* *$ & -2.88 & $* *$ & -10803 & $* *$ & 1.42 & $* *$ & -4.04 & $* *$ \\
\hline \multicolumn{12}{|c|}{ PANEL B LATEROUND } \\
\hline MAIN MARKET & EVENTS & NBETS & & AVBET & & VOLTOT & & NODDS & & SD & \\
\hline 1 & 14616 & 692.81 & & 228.32 & & 200357 & & 23.01 & & 1.65 & \\
\hline 0 & 10067 & 450.29 & & 143.46 & & 68472 & & 22.8 & & 1.58 & \\
\hline DIF & & 242.52 & $* *$ & 84.86 & ** & 131885 & ** & 0.21 & & 0.07 & \\
\hline ALTERNATIVE MARKET & EVENTS & NBETS & & AVBET & & VOLTOT & & NODDS & & SD & \\
\hline 1 & 14616 & 346.74 & & 44.03 & & 23987 & & 19.16 & & 7.52 & \\
\hline 0 & 10067 & 220.65 & & 34.94 & & 9751 & & 18.78 & & 5.12 & \\
\hline DIF & & 126.09 & $* *$ & 9.09 & $* *$ & 14236 & ** & 0.38 & $* *$ & 2.4 & ** \\
\hline \multicolumn{12}{|c|}{ PANEL C GRAND SLAM } \\
\hline MAIN MARKET & EVENTS & NBETS & & AVBET & & VOLTOT & & NODDS & & SD & \\
\hline 1 & 5643 & 738.18 & & 293.94 & & 278121 & & 21.83 & & 2.26 & \\
\hline 0 & 19040 & 551.14 & & 164 & & 107578 & & 23.25 & & 1.43 & \\
\hline DIF & & 187.04 & $* *$ & 129.94 & $* *$ & 170543 & ** & -1.42 & $* *$ & 0.83 & $* *$ \\
\hline ALTERNATIVE MARKET & EVENTS & NBETS & & AVBET & & VOLTOT & & NODDS & & SD & \\
\hline 1 & 5643 & 391.14 & & 43.88 & & 31313 & & 19.33 & & 12.69 & \\
\hline 0 & 19040 & 266.91 & & 39.27 & & 14289 & & 18.91 & & 4.72 & \\
\hline DIF & & 124.23 & ** & 4.61 & ** & 17024 & ** & 0.42 & ** & 7.97 & $* *$ \\
\hline
\end{tabular}




\section{TABLE 3}

This table gives the test results for the variable AbRIP (Result - Implied probability) for the different odds considered and the main and alternative markets. ${ }^{* *}$ and * denote coefficients significant at the $5 \%$ and $10 \%$ levels according to the $t$ statistic adjusted by the White (1980) procedure. The table also shows the test results from model (1) for the various odds estimates considered and for both the main and alternative markets using the SUR estimation method. **and * indicate levels of significance of $5 \%$ and $10 \%$, respectively.

\begin{tabular}{|c|c|c|c|c|c|c|}
\hline \multicolumn{7}{|c|}{ PANEL A } \\
\hline MAIN & VWODD & & EWODD & & HVOL & \\
\hline AbRIP & 0.0095 & $* *$ & 0.0314 & $* *$ & 0.0004 & \\
\hline MAIN & VWODD & & EWODD & & HVOL & \\
\hline C & -0.0537 & $* *$ & 0.0127 & $* *$ & -0.1129 & $* *$ \\
\hline GS & 0.0203 & $* *$ & 0.0213 & $* *$ & 0.0436 & $* *$ \\
\hline LOWRANK & 0.0309 & $* *$ & 0.0248 & $* *$ & 0.0206 & $* *$ \\
\hline LATEROUND & 0.0240 & $* *$ & 0.0080 & & 0.0256 & $* *$ \\
\hline \multicolumn{7}{|c|}{ PANEL B } \\
\hline ALTERNATIVE & VWODD & & EWODD & & HVOL & \\
\hline$(-1)^{*}$ AbRIP & 0.034370 & ** & 0.032581 & ** & 0.043334 & $* *$ \\
\hline ALTERNATIVE & VWODD & & EWODD & & HVOL & \\
\hline $\mathrm{C}$ & -0.0299 & ** & 0.0189 & ** & -0.0799 & $* *$ \\
\hline GS & 0.0133 & $* *$ & -0.0006 & & 0.0321 & $* *$ \\
\hline LOWRANK & 0.0368 & $* *$ & 0.0409 & $* *$ & 0.0306 & $* *$ \\
\hline LATEROUND & 0.0196 & $* *$ & -0.0009 & & 0.0184 & $* *$ \\
\hline
\end{tabular}




\section{TABLE 4}

The table shows the test results from model (2) for the various odds estimates considered and for both the main and alternative markets using the SUR estimation method. **and * indicate levels of significance of $5 \%$ and $10 \%$, respectively.

\begin{tabular}{|c|c|c|c|c|c|c|c|c|}
\hline \multicolumn{9}{|c|}{ PANEL A VWODD } \\
\hline & \multicolumn{2}{|l|}{ MAIN } & \multicolumn{2}{|c|}{ ALTERNATIVE } & \multicolumn{2}{|l|}{ MAIN } & \multicolumn{2}{|c|}{ ALTERNATIVE } \\
\hline C & -0.087633 & $* *$ & -0.024428 & & -0.134495 & $* *$ & -0.090880 & ** \\
\hline GS & & & & & 0.015093 & ** & 0.004189 & \\
\hline LOWRANK & & & & & 0.031173 & $* *$ & 0.041227 & ** \\
\hline LATEROUND & & & & & 0.015617 & $* *$ & 0.010600 & ** \\
\hline AbVOL & $1.60 \mathrm{E}-08$ & $* *$ & 4.09E-08 & & $1.59 \mathrm{E}-08$ & $* *$ & 2.26E-08 & \\
\hline AbAVBET & $-6.74 \mathrm{E}-06$ & & -0.000281 & $* *$ & $-4.28 \mathrm{E}-06$ & & -0.000200 & ** \\
\hline SD & 0.000124 & & -0.000109 & $* *$ & 0.000119 & & $-9.22 \mathrm{E}-05$ & * \\
\hline SKW & -0.040049 & $* *$ & 0.011587 & ** & -0.039988 & ** & 0.011949 & $* *$ \\
\hline RELATT & 0.080741 & $* *$ & 0.032728 & $* *$ & 0.098473 & $* *$ & 0.067189 & $* *$ \\
\hline R2 (\%) & 9,31 & & 1,82 & & 9,43 & & 2,08 & \\
\hline \multicolumn{9}{|c|}{ PANEL B EWODD } \\
\hline & \multicolumn{2}{|l|}{ MAIN } & \multicolumn{2}{|c|}{ ALTERNATIVE } & \multicolumn{2}{|l|}{ MAIN } & \multicolumn{2}{|c|}{ ALTERNATIVE } \\
\hline C & -0.396228 & $* *$ & -0.148310 & $* *$ & -0.445750 & $* *$ & -0.218501 & $* *$ \\
\hline GS & & & & & 0.015050 & $* *$ & 0.000369 & \\
\hline LOWRANK & & & & & 0.030536 & $* *$ & 0.042974 & $* *$ \\
\hline LATEROUND & & & & & 0.020319 & $* *$ & 0.012784 & $* *$ \\
\hline AbVOL & $1.69 \mathrm{E}-08$ & $* *$ & $-3.39 \mathrm{E}-09$ & & $1.74 \mathrm{E}-08$ & $* *$ & $-9.02 \mathrm{E}-09$ & \\
\hline AbAVBET & $-9.94 \mathrm{E}-06$ & & -0.000465 & $* *$ & $-7.21 \mathrm{E}-06$ & & -0.000386 & $* *$ \\
\hline SD & 0.268262 & $* *$ & -0.000988 & $* *$ & 0.271882 & $* *$ & -0.000964 & $* *$ \\
\hline SKW & -0.044485 & $* *$ & 0.005937 & $* *$ & -0.044702 & $* *$ & 0.006333 & $* *$ \\
\hline RELATT & 0.277597 & $* *$ & 0.112085 & $* *$ & 0.295038 & $* *$ & 0.148677 & $* *$ \\
\hline \multirow[t]{3}{*}{ R2 (\%) } & 6,01 & & 0 & & \multicolumn{2}{|l|}{6,13} & \multicolumn{2}{|l|}{0} \\
\hline & \multicolumn{4}{|c|}{ PANEL C HVOLODD } & & & & \\
\hline & \multicolumn{2}{|l|}{ MAIN } & \multicolumn{2}{|c|}{ ALTERNATIVE } & \multicolumn{2}{|l|}{ MAIN } & \multicolumn{2}{|c|}{ ALTERNATIVE } \\
\hline C & -0.307398 & $* *$ & -0.188221 & $* *$ & -0.354865 & $* *$ & -0.260120 & $* *$ \\
\hline GS & & & & & 0.026820 & $* *$ & 0.011836 & $* *$ \\
\hline LOWRANK & & & & & 0.031639 & $* *$ & 0.043920 & $* *$ \\
\hline LATEROUND & & & & & 0.021644 & $* *$ & 0.013656 & $* *$ \\
\hline AbVOL & $2.67 \mathrm{E}-08$ & $* *$ & $1.02 \mathrm{E}-07$ & $* *$ & 2.60E-08 & $* *$ & $7.69 \mathrm{E}-08$ & \\
\hline AbAVBET & $-2.61 \mathrm{E}-05$ & $* *$ & -0.000498 & $* *$ & $-2.22 \mathrm{E}-05$ & $* *$ & -0.000395 & $* *$ \\
\hline SD & $-2.41 \mathrm{E}-05$ & & -0.000118 & ** & $-3.76 \mathrm{E}-05$ & & $-9.58 \mathrm{E}-05$ & * \\
\hline SKW & -0.043443 & $* *$ & 0.016074 & ** & -0.043355 & $* *$ & 0.016493 & $* *$ \\
\hline RELATT & 0.227357 & $* *$ & 0.138159 & $* *$ & 0.240641 & $* *$ & 0.173392 & $* *$ \\
\hline R2 (\%) & 9,28 & & 0,93 & & 9,34 & & 1,1 & \\
\hline
\end{tabular}




\section{TABLE 5}

The table shows the test results from model (3) for the various odds estimates considered and for both the main and alternative market using the SUR estimation method. **and * indicate levels of significance of $5 \%$ and $10 \%$, respectively.

\begin{tabular}{|c|c|c|c|c|c|c|c|c|}
\hline \multicolumn{9}{|c|}{ PANEL A VWODD } \\
\hline & \multicolumn{2}{|l|}{ MAIN } & \multicolumn{2}{|c|}{ ALTERNATIVE } & \multicolumn{2}{|l|}{ MAIN } & \multicolumn{2}{|c|}{ ALTERNATIVE } \\
\hline C & -0.025965 & * & 0.014379 & & -0.048312 & $* *$ & -0.015550 & \\
\hline GS & & & & & 0.021617 & $* *$ & 0.015396 & ** \\
\hline LOWRANK & & & & & 0.011551 & $* *$ & 0.017830 & $* *$ \\
\hline LATEROUND & & & & & 0.019587 & $* *$ & 0.015902 & $* *$ \\
\hline AbVOL & $8.66 \mathrm{E}-08$ & $* *$ & 8.17E-08 & $* *$ & 8.61E-08 & $* *$ & $8.22 \mathrm{E}-08$ & $* *$ \\
\hline AbAVBET & $-5.27 \mathrm{E}-05$ & $* *$ & $-5.93 \mathrm{E}-05$ & $* *$ & $-5.30 \mathrm{E}-05$ & $* *$ & $-6.22 \mathrm{E}-05$ & $* *$ \\
\hline SD & 0.000789 & $* *$ & 0.000705 & $* *$ & 0.000772 & $* *$ & 0.000693 & $* *$ \\
\hline SKW & -0.132834 & $* *$ & -0.128241 & $* *$ & -0.132637 & $* *$ & -0.127937 & $* *$ \\
\hline RELATT & 0.054126 & $* *$ & 0.036650 & $* *$ & 0.055371 & $* *$ & 0.044922 & $* *$ \\
\hline R2 (\%) & 16,36 & & 14,05 & & 16,42 & & 14,13 & \\
\hline \multicolumn{9}{|c|}{ PANEL B EWODD } \\
\hline & \multicolumn{2}{|l|}{ MAIN } & \multicolumn{2}{|c|}{ ALTERNATIVE } & \multicolumn{2}{|l|}{ MAIN } & \multicolumn{2}{|c|}{ ALTERNATIVE } \\
\hline $\mathrm{C}$ & -0.291594 & $* *$ & -0.119825 & $* *$ & -0.313295 & $* *$ & -0.152349 & $* *$ \\
\hline GS & & & & & 0.020044 & $* *$ & 0.002292 & \\
\hline LOWRANK & & & & & 0.007040 & & 0.018551 & $* *$ \\
\hline LATEROUND & & & & & 0.025280 & $* *$ & 0.017278 & $* *$ \\
\hline AbVOL & $8.28 \mathrm{E}-08$ & $* *$ & $6.19 \mathrm{E}-08$ & $* *$ & $8.25 \mathrm{E}-08$ & $* *$ & $6.33 \mathrm{E}-08$ & ** \\
\hline AbAVBET & $-5.95 \mathrm{E}-05$ & $* *$ & $-6.59 \mathrm{E}-05$ & $* *$ & $-5.91 \mathrm{E}-05$ & $* *$ & $-7.03 E-05$ & $* *$ \\
\hline SD & 0.198654 & $* *$ & 0.000203 & $* *$ & 0.203886 & $* *$ & 0.000200 & $* *$ \\
\hline SKW & -0.124250 & $* *$ & -0.116384 & $* *$ & -0.124549 & $* *$ & -0.116092 & $* *$ \\
\hline RELATT & 0.237212 & $* *$ & 0.132151 & $* *$ & 0.236343 & $* *$ & 0.144068 & ** \\
\hline \multirow[t]{3}{*}{ R2 (\%) } & 11,39 & & 12,88 & & \multicolumn{2}{|l|}{11,48} & \multicolumn{2}{|l|}{12,96} \\
\hline & \multicolumn{4}{|c|}{ PANEL C HVOLODD } & & & & \\
\hline & \multicolumn{2}{|l|}{ MAIN } & \multicolumn{2}{|c|}{ ALTERNATIVE } & \multicolumn{2}{|l|}{ MAIN } & \multicolumn{2}{|c|}{ ALTERNATIVE } \\
\hline $\mathrm{C}$ & -0.357715 & $* *$ & -0.294097 & $* *$ & -0.397928 & $* *$ & -0.345147 & $* *$ \\
\hline GS & & & & & 0.039636 & $* *$ & 0.030518 & $* *$ \\
\hline LOWRANK & & & & & 0.022390 & $* *$ & 0.031561 & $* *$ \\
\hline LATEROUND & & & & & 0.028674 & $* *$ & 0.022248 & $* *$ \\
\hline AbVOL & $1.02 \mathrm{E}-07$ & $* *$ & 9.82E-08 & $* *$ & $1.02 \mathrm{E}-07$ & $* *$ & $9.93 \mathrm{E}-08$ & $* *$ \\
\hline AbAVBET & -0.000124 & $* *$ & -0.000128 & $* *$ & -0.000126 & $* *$ & -0.000134 & $* *$ \\
\hline SD & 0.000888 & $* *$ & 0.000809 & $* *$ & 0.000845 & $* *$ & 0.000777 & $* *$ \\
\hline SKW & -0.135764 & $* *$ & -0.137065 & $* *$ & -0.135443 & $* *$ & -0.136625 & $* *$ \\
\hline RELATT & 0.280133 & $* *$ & 0.248745 & $* *$ & 0.284897 & $* *$ & 0.264050 & $* *$ \\
\hline R2 (\%) & 14,03 & & 10,19 & & 14,07 & & 10,21 & \\
\hline
\end{tabular}




\section{TABLE 6}

This table gives the test results from model (3) for the various odds estimates considered and for both the main and alternative markets obtained via OLS with White (1980) standard errors in separate estimations of the equations in the system. **and * indicate levels of significance of $5 \%$ and $10 \%$, respectively.

\begin{tabular}{|c|c|c|c|c|c|c|c|c|}
\hline \multicolumn{9}{|c|}{ PANEL A VWODD } \\
\hline & \multicolumn{2}{|l|}{ MAIN } & \multicolumn{2}{|c|}{ ALTERNATIVE } & \multicolumn{2}{|l|}{ MAIN } & \multicolumn{2}{|c|}{ ALTERNATIVE } \\
\hline $\mathrm{C}$ & -0.085197 & $* *$ & -0.043093 & $* *$ & -0.124370 & $* *$ & -0.089811 & $* *$ \\
\hline GS & & & & & 0.016455 & $* *$ & 0.009670 & * \\
\hline LOWRANK & & & & & 0.024951 & $* *$ & 0.032618 & $* *$ \\
\hline LATEROUND & & & & & 0.010278 & $* *$ & 0.005482 & \\
\hline AbVOL & $5.80 \mathrm{E}-08$ & $* *$ & $4.89 \mathrm{E}-08$ & $* *$ & $6.00 \mathrm{E}-08$ & $* *$ & $5.21 \mathrm{E}-08$ & $* *$ \\
\hline AbAVBET & $-6.99 \mathrm{E}-05$ & $* *$ & $-7.57 \mathrm{E}-05$ & $* *$ & $-7.71 \mathrm{E}-05$ & $* *$ & $-8.56 \mathrm{E}-05$ & $* *$ \\
\hline SD & $-3.71 \mathrm{E}-05$ & & -0.000267 & $* *$ & $-4.19 \mathrm{E}-05$ & & -0.000267 & $* *$ \\
\hline SKW & -0.119211 & $* *$ & -0.112001 & $* *$ & -0.118996 & $* *$ & -0.111664 & $* *$ \\
\hline RELATT & 0.112109 & $* *$ & 0.093905 & $* *$ & 0.127988 & $* *$ & 0.117091 & $* *$ \\
\hline R2 (\%) & 16,85 & & 14,72 & & 16,94 & & 14,81 & \\
\hline \multicolumn{9}{|c|}{ PANEL B EWODD } \\
\hline & \multicolumn{2}{|l|}{ MAIN } & \multicolumn{2}{|c|}{ ALTERNATIVE } & \multicolumn{2}{|l|}{ MAIN } & \multicolumn{2}{|c|}{ ALTERNATIVE } \\
\hline $\mathrm{C}$ & -0.471710 & ** & -0.049236 & $* *$ & -0.498380 & $* *$ & -0.098768 & $* *$ \\
\hline GS & & & & & 0.024965 & $* *$ & 0.003899 & \\
\hline LOWRANK & & & & & 0.014816 & $* *$ & 0.035754 & $* *$ \\
\hline LATEROUND & & & & & 0.015935 & $* *$ & 0.002518 & \\
\hline AbVOL & $6.05 \mathrm{E}-08$ & $* *$ & $3.96 \mathrm{E}-08$ & $* *$ & 6.13E-08 & $* *$ & 4.31E-08 & $* *$ \\
\hline AbAVBET & $-4.43 \mathrm{E}-05$ & $* *$ & $-6.40 \mathrm{E}-05$ & $* *$ & $-4.74 \mathrm{E}-05$ & $* *$ & $-7.48 \mathrm{E}-05$ & $* *$ \\
\hline SD & 0.579548 & $* *$ & -0.000274 & $* *$ & 0.580969 & $* *$ & -0.000271 & $* *$ \\
\hline SKW & -0.139830 & $* *$ & -0.106599 & $* *$ & -0.139834 & $* *$ & -0.106128 & $* *$ \\
\hline RELATT & 0.348465 & $* *$ & 0.092763 & $* *$ & 0.353122 & $* *$ & 0.119725 & $* *$ \\
\hline \multirow[t]{3}{*}{ R2 (\%) } & 13,41 & & 13,34 & & \multicolumn{2}{|l|}{13,52} & \multicolumn{2}{|l|}{13,51} \\
\hline & \multicolumn{4}{|c|}{ PANEL C HVOLODD } & & & & \\
\hline & \multicolumn{2}{|l|}{ MAIN } & \multicolumn{2}{|c|}{ ALTERNATIVE } & \multicolumn{2}{|l|}{ MAIN } & \multicolumn{2}{|c|}{ ALTERNATIVE } \\
\hline $\mathrm{C}$ & -0.184176 & $* *$ & -0.048597 & $* *$ & -0.214771 & $* *$ & -0.087962 & $* *$ \\
\hline GS & & & & & 0.019414 & $* *$ & 0.005635 & \\
\hline LOWRANK & & & & & 0.018250 & $* *$ & 0.027251 & $* *$ \\
\hline LATEROUND & & & & & 0.013534 & $* *$ & 0.003216 & \\
\hline AbVOL & 6.31E-08 & $* *$ & 4.73E-08 & $* *$ & $6.41 \mathrm{E}-08$ & $* *$ & 5.02E-08 & $* *$ \\
\hline AbAVBET & $-8.48 \mathrm{E}-05$ & $* *$ & $-7.41 \mathrm{E}-05$ & $* *$ & $-8.92 \mathrm{E}-05$ & $* *$ & $-8.26 \mathrm{E}-05$ & $* *$ \\
\hline SD & -0.000179 & & -0.000544 & $* *$ & -0.000188 & & -0.000538 & $* *$ \\
\hline SKW & -0.115528 & $* *$ & -0.109333 & $* *$ & -0.115407 & $* *$ & -0.109084 & $* *$ \\
\hline RELATT & 0.182361 & $* *$ & 0.101602 & $* *$ & 0.191380 & $* *$ & 0.122270 & $* *$ \\
\hline R2 (\%) & 16,34 & & 13,74 & & 16,42 & & 13,82 & \\
\hline
\end{tabular}




\section{TABLE 7}

The table shows the test results from model (4) for the VWODD results and for both the main and alternative market using the SUR estimation method. **and * indicate levels of significance of $5 \%$ and $10 \%$, respectively.

\begin{tabular}{|c|c|c|c|c|c|c|c|c|}
\hline \multicolumn{9}{|c|}{ VWODD } \\
\hline \multirow[b]{2}{*}{ C } & \multicolumn{2}{|l|}{ MAIN } & \multicolumn{2}{|c|}{ ALTERNATIVE } & \multicolumn{2}{|l|}{ MAIN } & \multicolumn{2}{|c|}{ ALTERNATIVE } \\
\hline & -0.082335 & ** & -0.038213 & $* *$ & -0.125660 & $* *$ & -0.087730 & $* *$ \\
\hline GS & & & & & 0.002731 & & -0.003145 & \\
\hline LOWRANK & & & & & 0.022328 & $* *$ & 0.028215 & $* *$ \\
\hline LATEROUND & & & & & 0.012814 & ** & 0.009435 & $* *$ \\
\hline AbVOL & $6.28 \mathrm{E}-08$ & $* *$ & 6.17E-08 & $* *$ & $6.58 \mathrm{E}-08$ & ** & $6.45 \mathrm{E}-08$ & $* *$ \\
\hline AbAVBET & $-3.91 \mathrm{E}-05$ & $* *$ & $-4.82 \mathrm{E}-05$ & $* *$ & $-5.09 \mathrm{E}-05$ & ** & $-6.12 E-05$ & ** \\
\hline SD & 0.000736 & $* *$ & 0.000662 & $* *$ & 0.000741 & $* *$ & 0.000671 & $* *$ \\
\hline SKW & -0.130608 & ** & -0.126255 & $* *$ & -0.130377 & $* *$ & -0.125914 & $* *$ \\
\hline RELATT & 0.094914 & $* *$ & 0.074653 & $* *$ & 0.115886 & $* *$ & 0.101492 & $* *$ \\
\hline altAbVOL & $1.22 \mathrm{E}-07$ & $* *$ & $1.46 \mathrm{E}-07$ & $* *$ & 1.17E-07 & $* *$ & $1.27 \mathrm{E}-07$ & $* *$ \\
\hline altAbAVBET & -0.000555 & $* *$ & -0.000633 & $* *$ & -0.000495 & $* *$ & -0.000522 & $* *$ \\
\hline altSD & $-5.26 \mathrm{E}-05$ & & $-7.84 \mathrm{E}-05$ & & $-4.88 \mathrm{E}-05$ & & $-6.42 \mathrm{E}-05$ & \\
\hline altSKW & 0.063059 & $* *$ & 0.062617 & $* *$ & 0.063226 & $* *$ & 0.062968 & ** \\
\hline R2 (\%) & 19,73 & & 16,99 & & 19,83 & & 17,16 & \\
\hline
\end{tabular}




\section{TABLE 8}

The table shows the test results from model (3) excluding RELATT for the VWODD results for both the main and alternative market using the SUR estimation method. **and * indicate levels of significance of $5 \%$ and $10 \%$, respectively.

\begin{tabular}{|c|c|c|c|c|c|c|c|c|}
\hline \multicolumn{9}{|c|}{ PANEL A VWODD } \\
\hline & \multicolumn{2}{|l|}{ MAIN } & \multicolumn{2}{|c|}{ ALTERNATIVE } & \multicolumn{2}{|l|}{ MAIN } & \multicolumn{2}{|c|}{ ALTERNATIVE } \\
\hline $\mathrm{C}$ & 0.039161 & $* *$ & 0.057507 & $* *$ & 0.020900 & ** & 0.040233 & $* *$ \\
\hline GS & & & & & 0.024375 & ** & 0.017747 & $* *$ \\
\hline LOWRANK & & & & & 0.004767 & ** & 0.012079 & \\
\hline LATEROUND & & & & & 0.019468 & ** & 0.015890 & $* *$ \\
\hline AbVOL & $8.21 \mathrm{E}-08$ & $* *$ & 7.94E-08 & $* *$ & $8.13 \mathrm{E}-08$ & ** & $7.86 \mathrm{E}-08$ & $* *$ \\
\hline AbAVBET & $-3.01 E-05$ & $* *$ & $-4.37 \mathrm{E}-05$ & $* *$ & $-2.91 E-05$ & ** & $-4.26 \mathrm{E}-05$ & $* *$ \\
\hline SD & 0.000766 & $* *$ & 0.000690 & $* *$ & 0.000745 & ** & 0.000672 & $* *$ \\
\hline SKW & -0.132569 & $* *$ & -0.128020 & $* *$ & -0.132485 & ** & -0.127799 & $* *$ \\
\hline \multicolumn{9}{|l|}{ RELATT } \\
\hline R2 (\%) & 16,16 & & 13.87 & & 16.21 & & 13.93 & \\
\hline
\end{tabular}

